\title{
SUICIDE PREVENTION AND \\ MANAGEMENT IN THE SA NATIONAL \\ DEFENCE FORCE: A PSYCHOLOGICAL \\ DISCUSSION
}

\author{
Rene Koopman and Gielie van Dyk \\ Faculty of Military Science, Stellenbosch University
}

\begin{abstract}
Suicidal behaviour is a challenge for military forces around the world. Suicide can be a reaction in peacekeeping operations or conventional warfare, because the stressful nature of both types of operations can force military members to such a catastrophic end. This article focuses on the necessary knowledge and skills for a better understanding of suicidal behaviour in the South African National Defence Force (SANDF) for members on different levels. It discusses the operational environment, with specific reference to peacekeeping operations or conventional warfare as contributing factors, risk factors, and the prevention and proper management of suicide by means of educating commanders and members of the multi-professional team (MPT).
\end{abstract}

\section{Introduction}

doi:Suicidal behaviour is a worldwide challenge for military forces to prevent and manage. Suicide is the second most common cause of death in the United States military and also accounted for substantial mortality in the Russian military, among British veterans of the Falkland war and during the recent Iraq conflict. ${ }^{1}$ In the United States Military, where the active-duty military is comprised predominantly of young male adults (about 50\% are aged 17-26 years), a vast amount of money is spent on prevention and management of suicidal behaviour. ${ }^{2}$ During the 22-year period from 1984 to 2005, 638 suicides occurred among the United Kingdom (UK) regular armed forces: 624 among males, and 14 among

Scientia Militaria, South African Journal of Military Studies, Vol 40, Nr 1, 2012, pp. 117-138. doi: $10.5787 / 40-1-987$ females. Army males aged 20-24 years and those under the age of 20 years had the highest rates, at 18 and 16 per 100000 -strength respectively. ${ }^{3}$ The Canadian forces, which currently have about 60000 members, 
reported 66 suicides between January 1990 and July 1995, with one third of the victims having peacekeeping experience. ${ }^{4}$ This was the first demonstration that interpersonal traumatic events of peacekeeping operations, are associated with suicide attempts in a representative sample of active Canadian military men and women. ${ }^{5}$

The Nigerian military population is essentially a youthful population. Nigerian military personnel mostly live within multi-ethnic and multi-religious barrack communities. Statistics on suicidal behaviour in Nigeria, especially among the youth, are scarce. Research done over a five-year period shows a total of 13737 patients admitted to the Yaba military hospital, in Lagos, Nigeria. ${ }^{6}$ Of these admissions, only 51 attempted to commit suicide. Fifteen of the 51 who had attempted suicides were military personnel.

It is not only the military members in active service who struggle with suicidal behaviour. Nye reported in her research on Vietnam combat veterans, that posttraumatic stress disorder (PTS) symptoms are also good predictors of suicidal behaviour in these Vietnam veterans, ${ }^{7}$ while Mahon et al. report the same results on veterans from the Falkland war. ${ }^{8}$ Mahon et al. are of opinion that, like other employers, military installations are expected to maintain safe work environments to support employees' health. ${ }^{9}$ To maintain battle fitness, military forces need a proper policy and practice to prevent, manage and treat suicidal behaviour in the units and during operations.

\section{Suicide in the SANDF}

Before the first democratic election in 1994, suicidal behaviour presented a high-risk challenge to the former South African Defence Force (SADF). Young white males between the ages of 18 and 25 were forced by law under the P.W. Botha, National Party government, to serve two years in the military. Van Dyk conducted research on adjustment disorders among adolescents between the ages of 18 and 24 , using a sample containing a high number of SADF members. ${ }^{10}$ The results showed that between 10 and $57 \%$ of those members who received psychiatric treatment were diagnosed with adjustment disorders and were vulnerable to suicidal behaviour. A high number of these struggled with suicidal behaviour and during 1986, at the height of the South African counter-insurgency war, 453 SADF members committed or attempted to commit suicide. ${ }^{11}$

Suicide is also a form of violence that affected the SANDF after 1994. According to SANDF media liaison officer Major Fanus Pretorius, "suicide is 
accepted as a common phenomenon in defence forces (also in the SANDF) around the world" and as such can be regarded as a possible by-product of the military experience.

Between 1994 and 2000, almost 300 members of the SANDF committed suicide. Statistics provided by the military reveal that in 1999 alone, an average of four soldiers took their lives every month. ${ }^{12}$ Of these, a large number are believed to have been members of the former liberation armies. Statistics provided by the military for the purposes of this report, show that there were 2040 suicides and attempted suicides between 1990 and 2001. Of these 433 were suicides. ${ }^{13}$

Some suicide cases were reported in newspapers in South Africa. In the Cape Times of 6 October 2006, it was reported that in September 1999 Lieutenant Sibusiso Madubela went on a shooting spree at 1 South African Infantry Battalion at Tempe in Bloemfontein, killing seven people and injuring five before he killed himself. In another article dated 9 November 2008, a report on the first black female admiral read: "SANDF official still at work despite suicide attempt." The SANDF's first black female judge, Colonel Phildah Nomoye, doused herself with petrol and set herself alight in her garage. According to the report at least two senior officers claimed that Nomoye escaped sanction after some senior personnel accepted her explanation that she was "bewitched" when she tried to kill herself. ${ }^{14}$ On Monday 18 May 2009 another report was made on a corporal at the 101 Air Supply Unit in Centurion, South Africa, who shot himself after earlier killing his wife. ${ }^{15}$ Die Burger of 31 August 2011 reported that Rifleman Moseki Kethupilwe committed suicide at the Infantry School at Oudtshoorn. These reports clearly indicated that leadership should protect subordinates from the adverse effects of a stressful environment. ${ }^{16}$

Personal issues, such as work and family, are also contributing factors when it comes to suicide. Statistics between April 2000 and March 2001 indicate that 48 SANDF soldiers committed or attempted to commit suicide. ${ }^{17}$ This figure is not very high but the Sunday Times (8 October 2000) reported that these statistics could only be the tip of the iceberg.

There are more contributing factors to soldiers committing suicide, especially from the operational environment. The operational environment has its own stressors, which will also be discussed in this article. The purpose of the article is to provide insight on suicidal behaviour. It therefore focuses on the following goals:

- $\quad$ firstly, to define suicide; 
- $\quad$ secondly, the causes and psychodynamics of suicide will be discussed;

- thirdly, suicidal behaviour in the military environment with specific reference to peacekeeping operations and conventional warfare will be discussed; and

- $\quad$ lastly, the article will focus on military ethical guidelines for non-medical personnel to manage members with suicidal behaviour, as well as ways in which members of the MPT can sensitise commanders on the prevention and occupational wellbeing of military members.

\section{Defining concepts of suicidal behaviour}

Suicide does not have one universally accepted definition. It can however be defined, simply, as intentional self-inflicted death with evidence that the person intended to die, also known as completed suicide. ${ }^{18}$ Suicide occurs when a person ends his/her life. Suicide, by definition is therefore fatal because in the end, the result is death.

Suicidal behaviour includes three types of self-destructive acts: completed suicide, attempted suicide, and suicide gestures. Attempted suicide is an act of selfharm that is intended to result in death but does not; it is a non-fatal action. Frequently, suicide attempts involve at least some ambivalence about wishing to die and maybe a cry for help. ${ }^{19}$

Suicide gestures are seen as acts of self-harm unlikely to result in death. ${ }^{20}$ For example, people may slash their wrists but not deep enough to bleed to death, or they take an overdose of vitamins. Suicide gestures are cries for help. The persons are desperate but do not know how to ask for help. For others, suicide gestures are attempts to manipulate or control the people around them. For example, an individual abandoned by a lover may make a suicide gesture in an attempt to get the lover back. Thoughts and plans about suicide are called suicide ideations. These may reflect pleas for help from people who still wish to live and should not be dismissed lightly. Suicide ideation is related to suicidal gestures.

\section{Why do people commit suicide?}

Several authors have tried to answer the question of why people kill themselves. The answer varies from person to person. Freud wrote that suicides could be regarded as disguised murders. In his view, the suicidal person's goal is not so much self-destruction as the destruction of another person, a lost object with whom the person has identified. 
According to Freud, people who have lost a loved object internalises the object as part of themselves as a means of symbolically avoiding the loss. In addition to loving the object, however, they also hate the object for its desertion or rejection. ${ }^{21}$ The suicide attempt may then be an expression of aggression against the internalised object rather than aggression against the self. Because the person is not aware of the aggressive feelings toward the loved object, his/her suicidal feelings do not seem to have anything to do with the object or loss. ${ }^{22}$

On the other hand, the reply may involve that the person is trying to block out unbearable emotional pain and hurt. ${ }^{23}$ There are many other circumstances, which can contribute to someone's decision to end his/her life, but the person's feelings about those circumstances are more important than the circumstances themselves. All people who consider suicide feel that life is unbearable. They have an extreme sense of hopelessness, helplessness and desperation.

When people get to the point of contemplating suicide, they are often so distressed that they are unable to see any other options; they are in an emotional cul de sac. Under normal circumstances, individuals experiencing isolated stressful or traumatic events find ways of coping reasonably well. However, problems may arise when there is a build-up of these events over a period of time, pushing coping strategies to the limit. ${ }^{24}$

A slightly more elaborate list of reasons why people commit or attempt suicide follows. According to Hawton, this is just an outline. ${ }^{25}$

- Heroic suicide - someone voluntarily dies for the good of the group, for example, the Japanese kamikaze pilots at the end of World War II.

- Escape from an unbearable situation - this may be persecution, terminal illness, chronic misery or a stressful situation in the military.

- Romantic suicide - "My life is not worth living without him/her". This usually occurs among the young who have lost loved ones, or among people who have lived together for many years, and one of them passes away.

- An attempt to manipulate others - "If you don't do what I want, I'll kill myself". This is the basic theme here. However, the manipulation does not necessarily mean that the suicide attempt is not serious.

Usually by the time people get to the stage of thinking about suicide as an option, they are no longer able to evaluate their options in an objective manner. If they were not in such great distress many would have chosen a different option. Many suicidal people just want to get out of the never-ending emotional pain. 


\section{Causes of suicidal behaviour}

Suicidal behaviour usually results from the interaction of several factors. The decision to commit suicide is often clouded by many personal and social stressors. Typical events leading to the suicide act suggest a sequence of interpersonal troubles that seems to become progressively more pervasive in the individual's life. ${ }^{26}$ For example, a soldier can experience conflict with his instructor, while his girlfriend falls pregnant at home and his parents are going through a divorce. He may experience this overwhelming wave of emotions, as reactions to the events, as the end of his world. For him, the only possible solution in this emotional unstable situation is to commit suicide.

The theory is still discussed whether suicide is inwardly directed aggression. This idea dates back to Freud, who thought that the suicide's energy forces become misdirected in the sense that they turn inward on the person, as punishment for his/her "failure", or that the person feels this is what he/she deserves in the situation.

According to Hawton, Rodham and Evans, more recent ideas, based on personality research, suggest that the aggression involved is a little more diffuse than this. While those who kill themselves, obviously have turned on themselves, it would seem that people also feel considerable aggression toward the world and feel that they have been treated unjustly. ${ }^{27}$ For example, a soldier's aggression is directed against him/herself and because he/she has the perception that he/she is a failure, the soldier commits suicide to "punish" him/herself for his/her unsuccessful performance.

As stated above, there can be many causes as to why a person would want to consciously take his/her own life. It is very rare that someone dies by suicide because of one cause. However, according to Shea, untreated mental illness, which includes depression, substance abuse, schizophrenia and many other mental illnesses, is the main cause for the vast majority of suicide cases. ${ }^{28}$

Depression and suicide

Risk factors for suicide may be distinguished as distal or proximal. ${ }^{29}$ Distal factors are longstanding and enhance vulnerabilities to suicide, like a stressful marriage. Proximal factors are more immediate and influence the particular timing for a suicide attempt (like death of a colleague in war). Psychiatric conditions are also important distal factors. Approximately $90 \%$ of those who commit suicide 
suffer from at least one diagnosable psychiatric condition, with depression as the most important disorder. ${ }^{30}$

Depression can play an important role in suicidal behaviour and is actually the most common causal factor for suicidal behaviour. ${ }^{31}$ According to Heginbotham, it has been estimated that at least $80 \%$ of suicidal patients are depressed, and the rate of suicide among depressed individuals is 22 to 36 times higher than among nondepressed individuals. ${ }^{32}$ Depression is involved in over $50 \%$ of attempted suicides. Depressed individuals commit suicide because, from their perspective, life is not worth living. A frequent comment made by depressed individuals is, "I wish I were dead". People with depression do not have the energy to be creative and find other solutions. Depression can also leave them feeling "Part of me is already dead and suicide will help me finish it off."

The rate of suicide among depressed individuals would probably have been even higher was it not that many severely depressed patients simply do not have the energy to commit suicide. Because of this, many suicides occur after the individual had started to recover. The individuals are still depressed, but as they improve, they get more energy and are better able to carry out the suicidal act. ${ }^{33}$ It very often happens that troops in recovery after being hospitalised for depression for a couple of days, commit suicide the moment they have to return to their unit with all its stressful experiences.

Alcohol and suicide

Alcohol dependence is an important risk factor for suicidal behaviour. It is a well-established fact that alcoholics have a very high suicide rate. According to Sher, about $90 \%$ of people in Western countries use alcohol at some time in their lives, and $40 \%$ experience temporary or permanent alcohol-related impairment in some area of life as a result of drinking. ${ }^{34}$ Rossow and Amundsen conducted research on 40000 Norwegian military conscripts. ${ }^{35}$ Their results showed that the risk of suicide among alcohol abusers was $6,9 \%$ higher than among those who were not misusing alcohol. Further, the risk for alcoholics in the Norwegian military were higher in middle age (40 years and up) than among younger age groups.

In South Africa and in the SANDF, alcohol is part of the social culture. It is well known in the SANDF that members come together in a military bar for a couple of drinks after a big event like sport (soccer, rugby and cricket) or after completing an operation. Individuals struggling with issues and who are depressed, may often find their defence mechanisms such as to avoid or deny issues, start to 
fade away after a couple of drinks, resulting in their emotions taking over their cognitive ability and heightening the risk of suicide.

Schizophrenia and suicide

According to Melle and Johannesen, four out of ten people who suffer from schizophrenia attempt suicide, and one out of ten people who suffer from schizophrenia die by suicide. ${ }^{36}$ Thus, the diagnosis of schizophrenia should be considered an urgent matter, especially in the military, which is often associated with high-risk behaviour involving arms and ammunition.

Schizophrenia is a chronic mental disorder that affects people worldwide. ${ }^{37}$ People with schizophrenia often have hallucinations and delusions. They may hear voices, believe that other people are controlling their thoughts, believe that others can read their minds, or believe that others are plotting to harm them. ${ }^{38}$ These problems often make them fearful and cause them to withdraw from people. They become isolated and use suicide to free themselves.

Conflict, stress and suicide

A more contemporary psychodynamic explanation for suicide is that people commit suicide to escape conflict and stress. According to King, Schwab-stone and Fisher, a variety of investigations have indicated that those who attempted suicide experienced up to four times as many negative life events just prior to their attempts than non-attempters in a comparable period of time. ${ }^{39}$

When considering the effects of stress on suicide, one should also consider the role played by social support in moderating the effects of stress. Individuals who attempt suicide often have less social support than non-attempters, suggesting that the absence of support intensifies the effects of stress. ${ }^{40}$

It is noteworthy that stress experienced by individuals who commit suicide often involves losses such as deaths of relatives or friends resulting in a reduction of social support.

The above is relevant for military active members where troops experience high levels of stress in combat or in peacekeeping situations. Bartone wrote on stressors in peacekeeping operations and how these contribute to high levels of stress in troops. ${ }^{41}$ Bruwer did research on members of the SANDF and the stressors they experienced in peacekeeping operations. ${ }^{42}$ The results showed that long 
working hours, boredom, traumatic events and women who had died caused high levels of stress in members of the SANDF. Without proper management, these risky situations will make members of the SANDF vulnerable to suicidal behaviour.

Identification with the lost object

Identification occurs in individuals whose object relations are characterised by the need to identify with the object. By identification, the distance between subject and object is abolished. Certain psychodynamic theorists believe that depression is triggered by a stressful loss. Some theorists suggest that depressed individuals attempt to regain the lost object or person by identifying with it. If the object has been lost through death, the ultimate act of identification is one's own death, and thus it may be that attempts to identify with the lost person result in suicide.

According to Hendin, theorists in support of this explanation have pointed to what so-called anniversary suicides, where an individual commits suicide on the anniversary of the identified individual's death. ${ }^{43}$ An alternative explanation for anniversary suicides is that the anniversary brings back the individual's stress and despair, and the heightening stress caused by those factors leads to the suicide.

Self-punishment

When people do things of which they do not approve, they often punish themselves in a variety of little ways, such as depriving themselves of some pleasure or treat. Psychodynamic theories suggest that in extreme cases, this self-punishment can result in suicide. They suggest that the "bad me" and the "good me" get separated, and to punish the "bad me", the "good me" may kill the "bad me". 44

\section{Revenge}

Revenge may play a role in suicide in that it appears that some individuals commit suicide to make people around them feel sorry and guilty. This motivation is often reflected in suicide notes that say, in effect, "this would not have happened if you had not done this or that". This is frequently seen in troops who are powerless to attack the adults who control them. The troops commit suicide in an attempt to get back at the adults. ${ }^{45}$ The story in the well-known movie Full Metal Jacket is a good example. It shows a troop who committed suicide because he wanted revenge on his fellow troops, as well as on his instructor and on himself because he could not survive the challenging training circumstances. 


\section{Characteristics of the operational environment}

The operational environment for members of the SANDF is normally of a diverse nature. It can be peacekeeping operations in countries like Burundi, the Democratic Republic of Congo (DRC) and Sudan; or conventional warfare simulated by exercises in joint operations in Lohathla. The nature and stressors differ from operation to operation. The following section discusses firstly the challenges with peacekeeping operations, and then conventional warfare.

\section{Peacekeeping operations}

Peacekeeping operations have their own unique characteristics and impact on military personnel. Peacekeeping forces often face an unfriendly populace, come under fire, live in unhygienic conditions, and are separated from their families. In addition, peacekeeping missions put more strain on individuals who may already be vulnerable, have a pre-existing mental health condition, abuse alcohol, or are experiencing relationship problems. These have been deemed risk factors for suicide in peacekeepers specifically. ${ }^{46}$ Although military personnel are trained for peacekeeping operations, accumulating evidence indicates that deployment-related exposure to traumatic events is associated with mental health problems. ${ }^{47}$ Military personnel are exposed to high rates of traumatic events during participation in peacekeeping operations.

Operation Uphold Democracy in Haiti saw significant stress in US troops, including three suicides in the first 30 days of the mission. ${ }^{48}$ This reinforced the need for availability of mental health providers to provide prevention and early intervention to military personnel supporting peacekeeping missions.

Soldiers of the SANDF are involved in a high number of peacekeeping operations in Burundi, the DRC and Sudan in Africa. These soldiers are away from home for long periods and experience high stress levels amidst long working hours, ${ }^{49}$ boredom and traumatic incidents with child soldiers, women and children who die. ${ }^{50}$ The factors mentioned may contribute to the vulnerability of SANDF members in terms of suicidal behaviour. In this regard, psychological ambiguities in peacekeeping operations contribute to this feeling of vulnerability. The triangle model of responsibility was developed to explain the process.

The triangle model of responsibility (Figure 1$)^{51}$ was developed to organise prior analysis of responsibility and provide a complete account of what causes people to feel and be held responsible. According to the triangle model, 
responsibility at any given time is best viewed as a transaction between the following:

- the specific event that has occurred or is anticipated, for example the battle or mission;

- the prescriptions or rules that govern the event, for example rules or ethical codes; and

- the identity images the individual has that are relevant to the event and prescriptions, for example, soldier or parent.

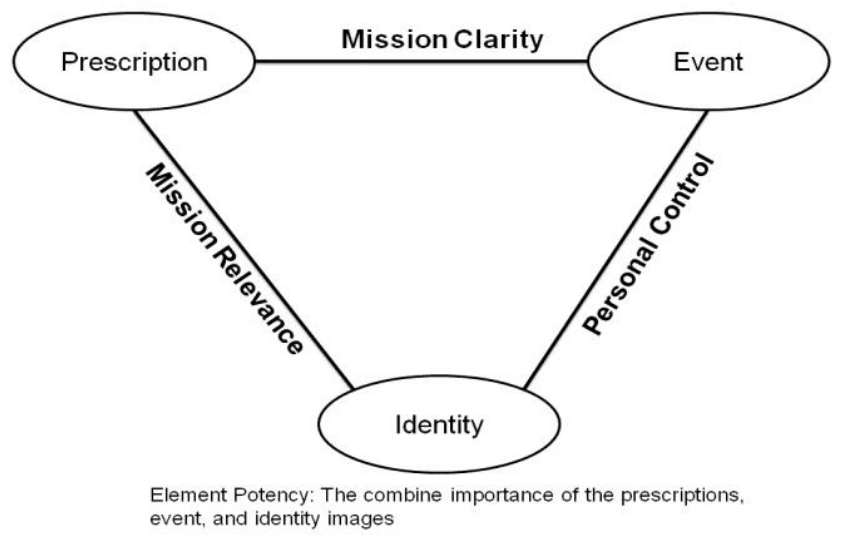

Figure 1: The triangle model of responsibility

The event, prescriptions, and identity images are the elements involved in any assessment of responsibility. The psychological ambiguities (Figure 1) soldiers experience during peacekeeping operations are discussed within this framework. The ambiguities come into play when the links are weak. If the peacekeeping mission relevance link is strong then the personal control link will be strong and vice versa. The identity, which is also referred to as the self or the individual, is the main focus of this model. The amount of personal control over the event will depend on how the identity accepts or abides with the prescriptions set out.

If the identity is a good-disciplined soldier, he will accept and abide by the rules and ethical values of the mission, therefore completing the mission successfully. However if, for example, the prescription of the event states that the soldier needs to be participating in the operation for a six-month period but 
simultaneously he/she needs to go home due to domestic problems, the soldier looses personal control and suicidal behaviour may set in.

If the soldier is not allowed to go home, the personal control weakens and this may bring about suicidal behaviour. This is also caused by the fact that the identity plays many roles of responsibility: being a soldier, a father, a husband and a peacekeeper. Once there is conflict between these roles of responsibility, ambiguity sets in and suicide may result from this conflict.

If there is no clarity on the peacekeeping mission, uncertainty is one of the factors in the operational environment that may lead to suicidal behaviour. Therefore, it is important for the identity to find equilibrium between the prescription and the event in order for it to maintain personal control over everything. The moment the identity loses personal control, negative behaviour results, including suicidal behaviour.

This model can sensitise commanders of the SANDF involved in peacekeeping operations in Africa to care for the well-being of their members, to manage the hygiene factors such as social support and family contact in order to maintain the esprit de corps as a method of prevention of suicidal behaviour.

Combat as a situation of stress

The one, all-pervading quality of combat, demarcating it as object of special interest, is that it contains a high element of stress. According to Cronin, stress is a term that means many things to many people; however, it is frequently used to describe two very different kinds of phenomena: stimuli in the environment (both physical and psychological, that may impinge upon the organism) and physical and psychological responses of the organism itself to such forces ${ }^{52}$. Stress in the military context refers to events or forces in the environment, outside the person, as opposed to subjective, internal responses.

According to Stouffer, Lumsdaine, Williams, Smith, Janis, Star and Cottrell, there are major factors, which soldiers everywhere tend to regard as things to be avoided during operations, namely adjustment to combat. This implies not only adjustment to killing, but also adjustment to danger, to frustration, to uncertainty, to noise and confusion and particularly to the wavering faith in the efficiency or success of commands. ${ }^{53}$ 
Conflict is also a factor that causes stress for soldiers during operations, especially when they are in conflict with one another. According to Jolly, conflict between military duty and obligations to family and dependants at home is one of those conflicted values that contribute to stress. ${ }^{54}$ Lack of privacy, long periods of enforced boredom, continual uncertainty, and deprivation of sexual and social satisfaction are but a few of other factors that also contribute to the stress of the conventional warfare environment. Kellet (in Glad) describes that in the battlefield environment, the troops are in isolation and they struggle with high levels of noise, fatigue, danger and casualties. ${ }^{55}$

Combat as the prime occasion of deliberate risks to life and limb imposes severe stress, involving the deepest anxieties and the most primitive threats to personal integrity ${ }^{56}$. There is also a great need for security, for feeling oneself as a valued person. Therefore, it is very important that the SANDF overcome the stigma and mindset of soldiers seeking psychological help to assist them in dealing with the stressors they experience during operations. Suicide in the military services is quite high, displaying a trend that has become extremely alarming, but which is easily overlooked.

The stigma associated with soldiers receiving psychological treatment has kept many from seeking help. Psychological problems are seen as a weakness in the military culture, resulting in many untreated soldiers. Soldiers may eventually feel that suicide is the only answer in order to escape the emotional pain that they are dealing with. ${ }^{57}$

\section{Military ethical guideline for non-medical personnel}

The ethical guidelines for medical doctors and psychologists in the Ethical code of professional conduct of South Africa are clear, whereas the military ethical guidelines for non-medical personnel in the SANDF are absent (Health Professions Council of South Africa (HPCSA), 2002). This article does not intend to interfere with the guidelines of the HPCSA, but the fourth goal is to sensitise psychologists from the MPT to educate commanders on different levels to manage suicidal behaviour in a more preventative and professional way than is currently the case.

The suicidal behaviour in the movie Full Metal Jacket is well known. If the fellow troop and instructor had followed some military ethical guidelines, they could have prevented the suicide attempt of the victim. 
Allen provides valuable ethical guidelines for non-medical personnel in the SANDF. ${ }^{58}$ The following military ethical guidelines can be helpful in cases of suicidal behaviour:

- respect for soldiers' dignity and rights: fellow soldiers need to treat soldiers with suicidal behaviour with dignity and help them in their vulnerable situation (not shout at them, no rejection, no punishment);

- responsible caring: such people need support, a safe environment (take away suicide possibilities like firearms), take responsibility for such person until he/she is in the hands of a member of the multi-professional team (MPT); and

- fellow soldiers need to establish boundaries to protect the member, to save his life, to secure his environment and to take him to the MPT.

In this regard, Britt, Castro and Adler focus on the preventative side and recommended that commanders and the MPT should focus on high morale and cohesion and protect stable personal lives of members to prevent suicidal behaviour. ${ }^{59}$ Schwerin (in Britt et al.) says the focus must be to protect the occupational well-being of members in operations to prevent suicide. ${ }^{60}$ Jones, Kennedy and Hourani (in Kennedy \& Zillmer) recommend the following steps to prevent and manage suicidal behaviour in militaries: ${ }^{61}$

- leadership involvement to apply a programme on proper management of suicidal behaviour;

- suicide prevention in professional military education, meaning to educate members on symptoms and management before they go on operations;

- leaders as gatekeepers, where the leaders are guardians of a unit climate and the mental health of members during training and operations;

- community prevention services, where the MPT educates, supports, refers and helps members with mental health vulnerabilities;

- annual suicide prevention training during normal training exercises;

- investigative interviewing by leaders on grass root level to facilitate solutions;

- critical event stress management, where platoon commanders and members of the MPT support members with symptoms of suicidal behaviour;

- integrated delivery system, community action and information board (in the SANDF, the Military Community Development Committee (MCDC)) where leadership discusses, plans and manages such members during an operation; 
- limited patient-psychotherapist privilege, where members of the MPT can do some psychotherapy with members before referral to a field hospital; and

- behavioural health survey, to evaluate mental health on the ground from time to time for management information and prevention.

\section{Prevention and management of suicidal behaviour in the SANDF}

A proposal for a model may exist in three dimensions as follows:

- prevention, to sensitise members and commanders regarding suicidal behaviour as a warning system for timely observation and referral;

- risk factors, to educate members and commanders through psycheducation to be sensitive about the tendency of more vulnerable members towards suicidal behaviour; and

- management, to implement a management plan to help members who are in trouble.

Suicide prevention in the military

Suicide ranks, after motor vehicle accidents and serious illnesses, as the third leading cause of non-battle-related deaths in the military. ${ }^{62}$ Given the impact of suicide on families and unit morale, efforts to prevent the loss of life and suffering have long been a part of the military counselling, chaplaincy and medical treatment.

It has been estimated that up to $90 \%$ of people who commit suicide have a psychiatric disorder, with mood disorders such as major depressive disorder and bipolar disorder constituting the most common diagnoses. Other psychiatric disorders associated with suicide are alcohol dependence, personality disorders, schizophrenia and anxiety disorders.

Feelings of hopelessness, however, are found to be more predictive of suicide risk than mental disorders. ${ }^{63}$ In recent years, suicide surveillance has become an important focus of the Department of Defence. Its Suicide Prevention and Risk Reduction Committees were created to formalise suicide prevention education and to improve the identification of and access to care for high-risk individuals. Commanders in the SANDF in units and in peacekeeping or combat operations need to implement policies on suicidal behaviour through their MPT, social worker, chaplain, psychologist, medical sister and operational medics. 
Members of the MPT can sensitise members in the units before operations on the symptoms, risks and prevention methods of suicidal behaviour. Such a preventative programme should become part of annual training for operations.

Risk factors and protective factors for suicide

Risk factors may be thought of as those factors leading to or being associated with suicide. People possessing the risk factor accordingly portray a greater potential for suicidal behaviour. Protective factors, on the other hand, reduce the likelihood of suicide. They enhance resilience and may serve to counterbalance risk factors. According to Masango, Rataemane and Matojesi, risk and protective factors may be biopsychosocial, environmental or socio-cultural by nature. ${ }^{64}$ Although this division is somewhat arbitrary, it provides the opportunity to consider these factors from different perspectives.

The impact of some risk factors can clearly be reduced by certain interventions, such as strengthening social support in a community. Risk factors that cannot be changed, such as a previous suicide attempt, can alert others to the heightened risk of suicide during periods of the recurrence of a mental or substance abuse disorder or following a significant stressful life event.

Protective factors are quite varied, and include an individual's attitudinal and behavioural characteristics, as well as attributes of the environment and culture. ${ }^{65}$ Some of the most important risk and protective factors are outlined below.

Protective factors for suicide

- Effective clinical care for mental, physical and substance use disorders;

- Easy access to a variety of clinical interventions and support for those seeking help;

- Restricted access to highly lethal means of suicide;

- Strong connections to family and community support; and

- Cultural and religious beliefs that discourage suicide and support selfpreservation.

However, positive resistance to suicide is not permanent, so programmes that support and maintain protection against suicide by the MPT should be ongoing. 
Risk factors for suicide

Biopsychosocial risk factors include family history of suicide, mental disorders, particularly mood disorders, schizophrenia and anxiety disorders, alcohol and other substance use disorders, hopelessness and aggressive tendencies. Environmental risk factors include job or financial loss, relational or social loss and local clusters of suicide that have a contagious influence.

Social-cultural risk factors include lack of social support and a sense of isolation, stigma associated with help-seeking behaviour, certain cultural and religious beliefs, for instance, the belief that suicide is a noble resolution to a personal dilemma and exposure to and influence of others, also through the media, who have died by suicide.

Members of the MPT need to educate platoon commanders and company commanders on these risk factors, as well as the need for timely identification and referral to the MPT at the unit sick bays or field hospitals during operations. Members with suicide vulnerabilities could be discussed on the MCDC of the SANDF for proper management of such members.

Management of suicidal behaviour in the SANDF

According to Weiner, the following guidelines for the assessment and management of suicidal individuals have been found to be useful to specific commanders at different levels, and for members of the MPT where relevant: ${ }^{66}$

First contact

The initial contact with suicidal persons is particularly important. It is important to recall that suicidal persons have often recently perceived rejection and a considerable degree of expertise and patience may be required in order to establish rapport. This can be achieved by indicating that one wishes to understand what is happening to that person and that a certain amount of time has been set aside in order to do so.

During first contact, the officer needs to bear in mind the risk factors, the possibility of depression and other psychiatric disorders, alcohol misuse and the removal of arms and ammunition. Following that, the member is taken by the hand to the MPT. 
Degree of suicidal intent

More direct questions may be necessary in order to elucidate the degree of suicidal intent. Suicidal thoughts and behaviour usually revolve around interpersonal phenomena, and the role of people of significance to the person should be sought. Open-ended questions such as "What are your feelings about living and dying" should be asked.

Such questions permit those with suicidal thoughts to express their feelings in a way that are not provided for by direct questions such as "Do you really want to kill yourself", which do not allow for the ambivalent feelings which are almost invariably present in suicidal persons.

Initial management

The most important initial decision is based on one's assessment of the safety of the suicidal person. The mere opportunity to ventilate thoughts and feelings to a concerned person may prove to be sufficient for some suicidal persons. If suicidal thoughts and actions have resulted in positive changes in personal relationships, further contact may be unnecessary, although the opportunity for further follow-up should be left open, particularly if there is inadequate social support. However, for those who are profoundly suicidal with a severe mental disorder, referral to the MPT will be necessary. If it was a successful suicide, members of the MPT will start with psychological debriefings, with members who stay behind, for the mental health of the group.

\section{Subsequent management}

Few persons require support for longer than two or three months, and this can involve three to six sessions, each of sufficient duration to allow the person to deal with his or her current interpersonal difficulties. It is usually beneficial to involve significant other people such as the person's partner, as the presence of a neutral therapist allows the expression of mixed feelings in a controlled manner. Those who engage in the care of persons who are suicidal must be willing to listen to the demands they may make. It is useful to insist that they clearly describe their options, other than suicidal behaviour, should they find themselves in a similar crisis in future. Commanders need to see that the member attends his/her follow-up sessions with the MPT and such treatment will normally be at the home unit, and not in the operational area. 


\section{Encouraging independence and coping skills}

There is a fine line between fostering independence and appearing to reject the suicidal individual. This can be overcome by making it quite clear that the therapist's involvement is time-limited and the expression of confidence in the individual's ability to cope in a more adaptive manner when future crises may arise. Although the aim is to encourage living independently, some persons, such as young single parents with little family and social support and patients with chronic mental disorders, will require longer-term supportive contact. The focus is to empower the member with coping skills to deal with such situations more constructively. The MPT will refer the member back to the home unit for this part of the treatment process.

\section{Use of physical treatment}

There is always concern about prescribing drugs when a person is suicidal, as there is inevitably some risk that the drugs themselves could be used in a suicide attempt. Having decided to utilise anti-depressants, it is imperative to use an adequate dose. It is also imperative to be aware of the potential risk of suicide associated with such drugs because of the toxicity of the anti-depressant used. The medical doctor will send the patient to the home unit for such treatment.

\section{Longer-term care}

Suicidal ideation and behaviour tend to recur, depending on the nature of ongoing interpersonal stressors, any associated mental disorder and stressors in the environment. The aim of all management should however be to enhance the coping skills and independence of patients.

There are also laws that govern the way psychotherapists and counsellors should manage suicide cases. There is even an anti-suicide contract that must be signed by the suicidal patient and the therapist in order to cover the therapist should the patient commit suicide. The therapist even has the right to inform the people concerned when it has been established beyond doubt that there is a possibility that the patient is going to commit suicide. ${ }^{67}$ Such cases will be sent home for long-term psychotherapy. 


\section{Conclusion}

Suicidal behaviour is part of militaries all over the world. It is necessary for militaries to develop the necessary knowledge and skills on suicidal behaviour. The proposed model for the SANDF focuses on prevention, risk factors around suicidal behaviour and proper management by commanders at different levels through timely identification and referral to the MPT at units or field hospitals during operations. The article also wants to sensitise members of the MPT to use psycho-education to equip commanders and members with the necessary knowledge and skills on suicide prevention and management.

\section{Endnotes}

${ }^{1}$ Mahon, MJ, Tobin, JP, Cusack, DA, Kelleher, C \& Malone, KM. "Suicide among regular-duty military personnel: A retrospective case-control study of occupation-specific risk factors for workplace suicide". American Journal of Psychiatry 162/9. 2005. 1688-1696.

${ }^{2}$ Martin, J, Ghahramanlou-Holloway, M, Lou, K \& Tucciarone, P. “A comparative review of US military and civilian suicide behaviour: Implications for OEF/OIF suicide prevention efforts". Journal of Mental Health Counselling 31/2. 2009. 101-118.

${ }^{3}$ Fear, NT. Suicide and open verdicts deaths in the UK regular armed forces, Defence Analytical Service Agency 1984-2005. 2006. <http:/www.barronpsych.com/au/research/UKArmysuicide2003.pdf> Accessed on 12 February 2010.

${ }^{4}$ Robb, N. "Links between suicide, peacekeeping duty probe". Canadian Medical Association Journal 156/5. 1997. 629.

${ }^{5}$ Belik, S, Stein, MB, Asmundson, GJG \& Sareen, J. "Relation between traumatic events and suicide attempts in Canadian military personnel". Canadian Journal of Psychiatry 54/2. 2009. 93-104.

${ }^{6}$ Okulate, GT. "Suicide attempts in a Nigerian military setting". East African Medical Journal 78/9. 2001. 493-496.

${ }^{7}$ Nye, EC. "Specific symptoms predict suicidal ideation in Vietnam combat veterans with chronic post-traumatic stress disorder". Military Medicine 172/11. 2007. 1144-1147.

${ }^{8}$ Mahon et al. op. cit.

${ }^{9}$ Ibid.

${ }^{10}$ Van Dyk, GAJ. “Aanpassingsversteurings: 'n Vergelykende psigologiese ondersoek". Unpublished PhD, PU for CHE, Potchefstroom, 1992.

${ }^{11}$ Stott, N. "From the SADF to SANDF: Safeguarding South Africa for a better life for all". Violence and Transition Series 7. 2002. 1-152.

${ }^{12}$ Ibid.

${ }^{13}$ Ibid. 
${ }^{14}$ African Crisis, 6 October 2006. <http://www.africancrisis.co.za> Accessed on 12 February 2010.

${ }^{15}$ Africa News, 9 November 2008. <http://news.iafrica.com/sa/1460538.htm> Accessed on 12 February 2010.

${ }^{16}$ Britt, TW. "How leaders can influence the impact that stressors have on soldiers". Military Medicine 169/7. 2004. 541-545.

${ }^{17}$ Stott op. cit.

${ }^{18}$ Hawton, K. The international handbook of suicide and attempted suicide. Chichester: Wiley, 2002.

${ }^{19}$ Holmes, D. Abnormal psychology, $2^{\text {nd }}$ ed. New York: Harper Collins, 1994.

${ }^{20}$ Shea, SC. The practical art of suicide assessment: A guide for mental health professionals and substance abuse. New York: Wiley, 2002.

${ }^{21}$ Huprich, SK. "Psychodynamic conceptual and treatment of suicidal patients". Journal of Contemporary Psychotherapy. 34/1. 2004. 23-39.

${ }^{22}$ Holmes op. cit.

${ }^{23}$ Joiner, T. Why people die by suicide. New York: Harvard University Press, 2005.

${ }^{24}$ Ibid.

${ }^{25}$ Hawton op. cit.

${ }^{26}$ McMahon, FB \& McMahon, JW. Abnormal behaviour psychology's view. Homewood, Ill: The Dorsey Press, 1983.

${ }^{27}$ Hawton, K, Rodham, K \& Evans, E. By their own young hands: Deliberate selfharm and suicidal ideas in adolescents. London: Jessica Kingsley, 2006.

${ }^{28}$ Shea op. cit.

${ }^{29}$ Allen, P. "Suicide in the army: A review of current information". Military Medicine 170/7. 2005. 580.

${ }^{30}$ Ibid.

${ }^{31}$ Okulate op. cit.

${ }^{32}$ Heginbotham, C. "Commentary on suicide, euthanasia and the psychiatrist". Philosophy, Psychiatry \& Psychology. 5/2. 1998. 137-139.

${ }^{33}$ Holmes op. cit.

${ }^{34}$ Sher, L. "Alcohol consumption and suicide". International Journal of Medicine 99/1. 2005. 57-61.

${ }^{35}$ Rossow, I \& Amundsen, A. "Alcohol abuse and suicide: A 40-year prospective study of Norwegian conscripts". Addiction 90. 1995. 685-691.

${ }^{36}$ Melle, I \& Johannesen, JO. "Early detection of the first episode of schizophrenia and suicidal behaviour". American Journal of Psychiatry 163/5. 2006. 800804.

${ }^{37}$ Harkavy-Friedman, JM. "Can early detection of psychosis prevent suicidal ${ }^{38}$ Ibid. behaviour?" American Journal of Psychiatry 163/5. 2006. 800-804.

${ }^{39}$ King, R, Schwab-Stone, M \& Fisher, A. "Psychosocial and risk behaviour correlates of youth suicide attempts and suicidal ideation". Journal of the American Academy of Child and Adolescent Psychiatry 40/7. 2001. 837846. 
${ }^{40}$ Hendin, H. "Psychodynamics of suicide with particular reference to the young". American Journal of Psychiatry 148. 1991. 1150-1158.

${ }^{41}$ Bartone, P. "Stress in the military setting. In Cronin, C (ed), Military psychology: An introduction. Needham Heights: Simon and Schuster, 1998, 113-146.

${ }^{42}$ Bruwer, N. "The South African peacekeeping experience: A comparative analysis". Unpublished master's thesis, Stellenbosch University, 2003.

${ }^{43}$ Hendin op. cit.

${ }^{44}$ Holmes op cit.

${ }^{45}$ Furst, SS \& Ostow, M. "The psychodynamics of suicide". New York Academy of Medicine 41/2. 1965. 190-204.

${ }^{46}$ Kennedy, C \& Zillmer, E. Military psychology: Clinical and operational applications. New York: The Guilford Press, 2006.

${ }^{47}$ Sareen, J, Stein, MB \& Meadows, G. "Combat and peacekeeping operations in relation to prevalence of mental disorders and perceived need for mental health care". Archives for General Psychiatry 64/7. 2007. 843-852.

${ }^{48}$ Cronin, C. Military psychology: An introduction. New York: Simon \& Schuster, 1998.

${ }^{49}$ Bruwer op. cit.

${ }^{50}$ Seedat, S. "Prevalence and characteristics of trauma and post-traumatic stress symptoms in operational members of the South African National Defence Force". Military Medicine 168/1. 2003. 71-75.

${ }^{51}$ Langholtz, HJ. The psychology of peacekeeping. Westport: Praeger, 1998.

${ }^{52}$ Cronin op. cit.

${ }^{53}$ Stouffer, SA, Lumsdaine, AA, Lumsdaine, MH, Williams, RM, Smith, MB, Janis, IL, Star, SA \& Cottrell, LS. The American soldier: Combat and its aftermath. New York: Princeton University Press, 1949.

${ }^{54}$ Jolly, R. Military man family man. Sydney: Brassey's Defence Publishers, 1987.

${ }^{55}$ Glad, B. Psychological dimensions of war. London: Sage, 1990.

${ }^{56}$ Cronin op. cit.

${ }^{57}$ Thoresen, S. "Risk factors for fatal accidents and suicides in peacekeepers: Is there an overlap?" Military Medicine 169/12. 2004. 988-993.

${ }^{58}$ Allen, A. The law for psychotherapists and counsellors, $2^{\text {nd }}$ ed. Somerset West: Inter-Ed, 2001.

${ }^{59}$ Britt, TW, Adler, AB \& Castro, CA. Military life: The psychology of serving in peace and combat. London: Praeger Security International, 2006.

${ }^{60}$ Ibid.

${ }^{61}$ Kennedy \& Zilmer op. cit.

${ }^{62}$ Ibid.

${ }^{63}$ Thoresen, S, Mehlum, L \& Moller, B. "Suicide in peacekeepers". Social Psychiatry \& Psychiatric Epidemiology 38/11. 2004. 605-610.

${ }^{64}$ Masango, SM, Rataemane, ST \& Motojesi, AA. "Suicide and suicide risk factors: A literature review”. SA Family Practice Journal 50/6. 2008. 25-29.

${ }^{65}$ Thoresen op. cit.

${ }^{66}$ Weiner, IB. Psychological disturbance in adolescence. New York: Wiley, 1970.

${ }^{67}$ Allen op. cit. 